\title{
Preface to the second decade
}

\author{
Atilla Ansal
}

Published online: 8 January 2013

C Springer Science+Business Media Dordrecht 2013

With this first issue of 2013 (Vol. 11 No.1), we are celebrating our tenth anniversary, our first decade. It has been ten exciting and inspiring years. This would not have been possible without the contributions of the distinguished BEE Editorial Board, distinguished authors of the published manuscripts and the competent, dedicated reviewers. I like to express my utmost gratitude and thanks to all who made this possible.

Furthermore, I would like to express my and our gratitude and thanks to Springer, specially to Petra D. van Steenbergen, Senior Publishing Editor of Earth Sciences, to Stefan van Dijl, Desk Editor, and to Geetha Subramanian, JEO Assistant from Journals Editorial Office for their continuous contributions, interest, and support.

During these past ten years, approximately 1,000 (to be exact 961) manuscripts were submitted for publication to BEE. The number of submitted manuscripts has increased continuously from 26 in 2003 and 2004, to 38 in 2005, 51 in 2006, 65 in 2007, 107 in 2008, 126 in 2009, 150 in 2010, 154 in 2011, and 243 in 2012. With respect to printed manuscripts; the first BEE volume in 2003 had 16, the second volume in 2004 had 15, and the third volume in 2005 had 12 articles. Due to the increase in the number of annual issues to four, the fourth volume in 2006 had 25, the fifth volume in 2007 had 27, the sixth volume in 2008 had 34, and the seventh volume in 2009 had 33 articles. In 2010, we have started to publish six issues and the number of published articles increased to 77 in 2010, 94 in 2011 and 88 in 2012.

Approximately 4 years after we started to publish BEE, I was informed on November 4, 2006 by Springer that BEE has been selected by ISI and will be included in SCIE and $\mathrm{CC} /$ Engineering, Computing, and Technology starting from the first issue of 2007. We started with the impact factor of 1.125 for 2007 which was the second highest among the five earthquake engineering journals (Earthquake Engineering and Structural Dynamics, Bulletin of Earthquake Engineering, Earthquake Spectra, Soil Dynamics and Earthquake Engineering, Journal of Earthquake Engineering) at that time. Our impact factor increased continuously in the following years to 1.271 for $2008,1.339$ for $2009,1.701$ for 2010 and 1.559 for

A. Ansal $(\bowtie)$

School of Engineering, Özyeğin University, Çekmeköy, Istanbul, Turkey

e-mail: atilla.ansal@ozyegin.edu.tr 
2011 again as the second highest among the present six earthquake engineering journals (Earthquake Engineering and Structural Dynamics, Bulletin of Earthquake Engineering, Earthquake Spectra, Soil Dynamics and Earthquake Engineering, Journal of Earthquake Engineering, and Earthquake Engineering and Engineering Vibration).

This first issue of 2013 is a special issue on Recent Major Earthquakes. The initial idea was based on the suggestions of Antonios Pomonis, Sean Wilkinson, and Gopal Madabushi and later developed as the collection of articles submitted to BEE related to recent major earthquakes. The first article in this issue is the Second Prof. Nicholas Ambraseys Distinguished Lecture delivered by Prof. Ezio Faccioli in Moscow during the 33rd General Assembly of the European Seismological Commission. The title "Recent Evolution and Challenges in the Seismic Hazard Analysis of the Po Plain Region, Northern Italy" was suggested few months prior to May and June earthquake sequence that was experienced in the Po Plain. We are in the process of editing another special issue on "The earthquake sequence that struck Emilia region, Italy, in May 2012" but we thought it would be more suitable to publish this manuscript before the special issue on Emilia Earthquake, as in the case of the proposal for the lecture title before the real earthquake.

This Special issue is composed of 11 manuscripts in chronological order related to 2010 Haiti Earthquake (1), 2010 Chile Earthquake (1), 2010 El Mayor-Cucapah Mexico Earthquake (1), 2011 Christchurch earthquake in New Zealand (1), 2011 Tohoko, Japan Earthquake (3), 2011 Myanmar Earthquake (1), 2011 Simav Turkey Earthquake (1), 2011 Van Turkey earthquake (2). We included an additional manuscript by Emily So and Robin Spence on "Estimating Shaking-induced Casualties and Building Damage for Global Earthquakes" which appears to be very suitable in the present special issue on recent major earthquakes. 